\title{
Economia, Instituições e Estado de Bem-Estar Social: Respostas à Nova Configuração do Capitalismo pós-1970*
}

\section{Alexandre Queiroz Guimarães}

Escola de Governo da Fundação João Pinheiro, Belo Horizonte, MG, Brasil.

E-mail: alexandre.queiroz@fjp.mg.gov.br

\section{INTRODUÇÃO}

$\mathrm{N}$ as décadas que se seguiram à Segunda Guerra Mundial, altas taxas de crescimento econômico e uma conjuntura favorável permitiram a conciliação sem precedentes entre prosperidade material e inclusão social, traduzida na consolidação de amplos Estados de bem-estar social. A combinação favorável de fatores, no entanto, perdurou por pouco tempo e as dificuldades do capitalismo vieram à tona a partir dos anos 1970, traduzindo-se em aumento do desemprego e em dificuldades para financiar as políticas de bem-estar social. O consenso social-democrata foi abalado, abrindo espaço para propostas alternativas.

$\mathrm{O}$ artigo explora as respostas a esses constrangimentos, focando principalmente nas mudanças nos Estados de bem-estar social. As dificuldades enfrentadas motivaram interpretações extremas. Um exemplo é a interpretação de que os constrangimentos macroeconômicos inviabilizaram a preservação de Estados de bem-estar social abrangentes, pressionando os países a reestruturações que os capacitassem a com-

\footnotetext{
* Agradeço a Lucas Borges pela contribuição em reflexões anteriores a esse texto, ao apoio da Fundação de Amparo à Pesquisa do Estado de Minas Gerais (Fapemig) e da Coordenação de Aperfeiçoamento de Pessoal de Nível Superior (Capes) e às observações dos dois pareceristas anônimos de DADOS-Revista de Ciências Sociais, que muito fortaleceram o artigo.
}

DADOS - Revista de Ciências Sociais, Rio de Janeiro, vol. 58, nํ3, 2015, pp. 617 a 650. 
petir na economia internacional. Outra interpretação condena o arranjo adotado como a consolidação de um consenso liberal em prejuízo dos direitos sociais.

O artigo procura mostrar porque essas interpretações são incapazes de abarcar o processo de transformação. Para isto, explora as inter-relações dos constrangimentos econômicos, das características institucionais domésticas e das reconfigurações no Estado de Bem-Estar Social. Argumenta-se que as mudanças na ordem internacional, apesar de significativas, não implicam trajetórias inexoráveis. O estudo retrata como as instituições, incluindo as características dos Estados de bemestar social, têm papel fundamental para explicar as respostas. Um ponto central é apresentar como certas respostas podem ser interpretadas como passos para preservar aspectos centrais do Estado de Bem-Estar Social.

Atenção especial é dada a dois conjuntos de respostas. Inicialmente, mostra-se como o neoliberalismo se configura como um conjunto de preceitos que oferece uma alternativa ao impasse dos anos 1970. No outro extremo, exploram-se as respostas dos países escandinavos, demostrando como foram conciliadas com a preservação de aspectos centrais do Welfare State. Destaca-se o papel do corporativismo e da capacidade institucional para o sucesso das reformas.

Importância central é conferida a mudanças no mundo do trabalho. Após anos de altas taxas de desemprego, medidas foram adotadas na direção de conciliar o desempenho do mercado de trabalho e a preservação da proteção social. O tratamento das políticas de emprego se justifica tanto por ser essencial para a viabilidade do Estado de BemEstar Social como por ilustrar a "recalibragem" necessária para preservar a proteção social.

Em síntese, o artigo aborda pontos centrais no estudo da economia política. Primeiro, por lidar com um aspecto central para a legitimidade do capitalismo, a capacidade de conciliar desempenho e igualdade. Segundo, por explorar o impacto das instituições e mostrar que o capitalismo continua diverso, não havendo convergência em direção a um modelo. O percurso empreendido é essencial para interpretar os processos de mudança e entender os desafios atuais. É também essencial para evitar o determinismo presente em certas interpretações que, além de empobrecer o fenômeno, traz implícitas implicações políticas. 
A próxima seção explora o contexto internacional e as mudanças ocorridas a partir dos anos 1970, indicando os impactos sobre a capacidade de financiamento do Estado de Bem-Estar Social. A seção seguinte lida com as respostas imediatas aos desafios, enfatizando a tendência à constituição de um trade off entre desempenho (emprego) e igualdade. Em seguida o artigo aborda os principais constrangimentos e pressões por reformas, avaliando o grau de mudança e recuo verificado nos Estados de bem-estar social. A seguinte explora a resposta inovadora, adotada pela Dinamarca, aos desafios do mundo do trabalho. Enfim, a penúltima seção aprofunda aspectos da resposta escandinava, destacando a capacidade de preservação das práticas igualitárias. A última traça as considerações finais.

\section{OS ANOS 1970 E 0 ABALO DO CONSENSO SOCIAL-DEMOCRATA}

O período entre o final da década de 1940 e o início dos anos 1970, conhecido como idade de ouro do capitalismo, caracterizou-se por altas taxas de crescimento, pleno emprego e aumento dos direitos sociais. Houve ampla melhoria na qualidade de vida, diversificação no padrão de consumo, aumento da expectativa de vida e avanços na seguridade social. A capacidade de conciliar prosperidade econômica e melhoria nos direitos sociais fortaleceu a legitimidade do regime.

Esses resultados se assentaram em uma rara combinação de condições favoráveis. Internacionalmente, o período caracterizou-se pela estabilidade na ordem econômica, alcançada pelas instituições de Bretton Woods. O Sistema de Bretton Woods (SBW), estabelecido em 1948, concedia aos governos nacionais certa autonomia na promoção dos objetivos nacionais, mas o fazia em um sistema de taxas de câmbio fixas, que visava evitar as práticas de desvalorizações competitivas ocorridas nos anos 1930. A promoção da abertura comercial, efetuada pelo Tratado Geral de Tarifas e Comércio (GATT), contribuiu para altas taxas de crescimento do comércio internacional (Borges e Guimarães, 2011).

Domesticamente, o crescimento se ancorou nos aumentos de produtividade e nas oportunidades de investimento acarretadas pelo surgimento de novos setores e pela expansão do consumo. A disseminação do fordismo, que se ancorava em rotinas de trabalho padronizadas e nas linhas de montagem, propiciou enormes ganhos de produtividade por meio de economias de escala e da simplificação do trabalho (ibidem $)^{1}$. Por sua vez, os setores automobilístico, farmacêutico, eletro- 
eletrônico, alimentício e de turismo, entre outros, puxaram os investimentos. Havia amplo mercado e oportunidades para as empresas se instalarem em outros países (Judt, 2008) ${ }^{2}$.

Os trabalhadores estavam organizados em sindicatos fortes. Este período foi marcado pela consolidação de contratos assalariados estáveis, em que os trabalhadores obtiveram ampla gama de direitos e serviços. O desemprego era basicamente friccional. Os salários cresceram significativamente, o que, ao lado das políticas macroeconômicas keynesianas, contribuiu para manter a demanda aquecida (ibidem). As instituições do Welfare State, oferecendo seguridade social, educação e treinamento, contribuíam para a harmonia social. A social-democracia tornou-se hegemônica, sendo sua agenda, em diversos países, absorvida pelos partidos conservadores ${ }^{3}$.

A ordem do pós-guerra trouxe uma prosperidade sem precedentes, conciliando melhoria no padrão de vida, apoio social e legitimidade. Estava, no entanto, alicerçada em características peculiares que permitiam o aumento, ao mesmo tempo, dos investimentos, do emprego, dos salários e dos lucros. Tal situação era rara e, devido aos elementos inerentes ao capitalismo, improvável de perdurar. O que se ignorava é quão dependente o edifício social-democrata era do desempenho da economia e, portanto, bem menos dependente das políticas keynesianas do que se pensava (Gamble, 1988).

Nos anos 1970, os setores que puxaram a expansão perderam fôlego. Ao mesmo tempo, novos produtores ampliaram a competição e a oferta, contribuindo para a redução dos preços. A situação de pleno emprego, aliada ao poder dos sindicatos, ampliava as pressões por aumento dos salários, representando pressão adicional sobre a taxa de lucro (Arrighi, 2008). Enfim, houve o estancamento do ritmo de crescimento da produtividade, resultado do esgotamento do fordismo e das dificuldades inerentes a este padrão, que incluíam a excessiva rigidez.

Dificuldades surgiram também no front internacional, fruto dos déficits norte-americanos no balanço de pagamentos e dos efeitos negativos sobre o padrão monetário baseado no lastro ouro-dólar, levando, em 1971, ao abandono da conversibilidade e, em 1973, à adoção de um regime de taxas de câmbio flutuantes. A ruptura do padrão trouxe incerteza e prejudicou o comércio. OSistema de Bretton Woods, embora deixando aberta a possibilidade de desvalorizações, levava os países a se preocuparem com a inflação, dado que não podiam desvalorizar o 
câmbio recorrentemente. Com a mudança nas regras, os países passaram a responder às dificuldades com emissão de moeda, causando inflação e a ulterior desvalorização do câmbio (Gamble, 1988).

Como consequência, o período 1971-1973 foi marcado por enorme liquidez internacional, frequentes desvalorizações cambiais e pressões inflacionárias. O preço das mercadorias subiu 70\%, o dos alimentos $100 \%$. É nesse contexto que se insere o choque do petróleo, lançando o mundo em recessão. O aumento dos preços do petróleo significou a aceleração das pressões inflacionárias, forçando os países a cortar gastos no intuito de enfrentar a inflação e as pressões no balanço de pagamentos.

Uma importante implicação diz respeito à impotência das políticas de estímulo à demanda. Inicialmente, porque agravariam o quadro inflacionário. Em segundo lugar, porque tenderiam a causar dificuldades no balanço de pagamentos, potencializadas por outra importante mudança, a desregulamentação das operações financeiras e a maior mobilidade no fluxo de capitais ${ }^{4}$. A partir de então, países que adotassem políticas expansionistas, sinalizando para pressões inflacionárias, tenderiam a sofrer fuga de capitais. Como resultado, o controle da inflação tornou-se o principal objetivo, uma mudança com fortes implicações sobre o mundo do trabalho.

Assim, os eventos do início da década de 1970 abalaram os alicerces da prosperidade anterior. $\mathrm{O}$ menor crescimento da arrecadação colocou dificuldades para o financiamento do Welfare State e, em face das altas expectativas, também para a governabilidade dos programas socialdemocratas. Outro foco de mudanças veio com o esgotamento do padrão fordista e com a introdução de novas técnicas de produção, que tiveram o duplo impacto de reduzir a demanda por trabalhadores na indústria e modificar o perfil dos trabalhadores exigidos.

Todo este quadro significou dificuldades para os trabalhadores. A competição crescente por parte de países com menores custos ameaçou a viabilidade de certos setores. Em segundo lugar, as mudanças no processo produtivo reduziram a demanda por trabalhadores menos qualificados, aquela parte da força de trabalho que mais havia crescido. Em terceiro, em um ambiente mais volátil as firmas passaram a demandar regras trabalhistas menos rígidas (Borges e Guimarães, 2011). 
Em síntese, estava-se diante de profundo processo de mudança estrutural. Houve enorme diminuição do emprego na indústria, enquanto a tentativa das empresas em driblar aspectos rígidos do contrato traduziu-se em práticas como subcontratação e terceirização. Além do desemprego crescente, houve a precarização dos postos de trabalho, uma vez que grande parte dos empregos gerados passou a ser em tempo parcial ou por prazo determinado, oferecendo menores direitos. $\mathrm{O}$ quadro de economias baseadas na indústria, com baixo grau de segmentação entre trabalhadores qualificados e não qualificados, desaparece, substituído por uma economia fluida e pelo aumento do desemprego de longo prazo (Kerstenetzky, 2012:73).

Em face do novo quadro, uma questão fundamental diz respeito à capacidade de resposta. Bem diferente dos anos 1960, a década de 1970 foi marcada por impotência e desilusão (Judt, 2008). À semelhança dos anos 1930, os policymakers não sabiam como responder. A magnitude das dificuldades chocava-se com o sucesso anterior, enquanto o fortalecimento de certos grupos dificultava a adoção de reformas.

\section{ENFRENTANDO OS DESAFIOS: PADRÕES DIFERENTES DE RESPOSTAS}

A crise, o aumento dos déficits públicos e o novo patamar de desemprego sinalizaram a ocorrência de mudanças profundas. Uma implicação central se deu sobre a capacidade de os governos entregarem o que haviam prometido, contribuindo para desacreditar certos pilares do pacto social-democrata. Em alguns países, a crise abriu a agenda política para que lideranças hábeis ocupassem espaço com um novo receituário (Gourevitch, 1986).

Como reação imediata, os governos se abraçaram às práticas vigentes. O protecionismo e outras formas de regulação foram restaurados, na tentativa de salvar os empregos ameaçados (Judt, 2008). Com o tempo, percebeu-se que as mudanças exigiam reformas profundas. As respostas foram influenciadas pelas características institucionais de cada país, incluindo a organização dos sindicatos e o tipo de Welfare State. Apresentaremos a seguir a resposta dividindo os países em três clusters, que em grande parte refletem a divisão original feita pelo trabalho clássico de Esping-Andersen (1990). A análise compartilha o que Hay e Wincott (2012) classificam como modelos de welfare capitalism que, ao lado das características do Welfare State, incorporam outros elementos inerentes às respectivas economias 5 . 
Em um primeiro cluster, de tradição anglo-saxã, o vácuo aberto pela crise foi ocupado pela agenda neoliberal. A capacidade de esta agenda ocupar o espaço, recuperando preceitos e direções que pareciam superados, deveu-se à existência de um elaborado pensamento que havia sobrevivido aos anos de hegemonia social-democrata (Gamble, 1988). Este conjunto de ideias, conhecido como a New Right, era mais que um pensamento econômico, contendo teorias sobre o Estado e sobre as instituições. Um dos seus pilares era a necessidade de conter a intervenção do Estado, uma vez que considerava a social-democracia a responsável pelas dificuldades econômicas.

Apesar de se basear em preceitos aceitos antes de 1930, a New Right apresentava-se como um pensamento original. Uma novidade era a combinação da defesa da livre economia com um pensamento conservador que defendia a autoridade do Estado. Um Estado forte era considerado fundamental para derrotar os grupos de interesse, incluindo os sindicatos e os servidores públicos, cujas demandas por proteção prejudicavam o funcionamento da economia (Gamble, 1988).

Inicialmente, era necessário recuperar as condições para o funcionamento do mercado, o que exigia uma política monetária rígida e orçamentos equilibrados. O controle da inflação era prioridade, uma vez que ameaçava os pilares da economia de mercado. Os sindicatos deveriam ser enfraquecidos, os impostos reduzidos e a economia desregulada, visando criar as condições para a recuperação do investimento e do emprego.

Outro pilar da New Right era a Teoria da Escolha Pública: políticos e burocratas eram vistos não como agentes voltados à promoção do bem geral, mas como atores voltados a maximizar as chances de reeleição e de ascensão nas carreiras. Estes desenvolvem contatos diferenciados com grupos econômicos, conferindo aos mais organizados canais privilegiados para a inserção de demandas. A New Right colocava em xeque os resultados de algumas decisões políticas e democráticas, consideradas inferiores às decisões do mercado. Uma implicação é que a intervenção estatal, acusada de favorecer alguns grupos, passa a ser criticada também em termos morais (ibidem).

A Grã-Bretanha ilustra o movimento de ascensão da New Right. O país sofreu os impasses dos anos 1970, compartilhando o recrudescimento da inflação e as pressões para a desindustrialização. Uma particularidade era a organização sindical: os sindicatos eram fortes, mas falta- 
vam organizações representativas que favorecessem a negociação com o governo e com os empresários. Houve a tentativa, malsucedida, de construção de mecanismos de negociação tripartite. A resistência dos trabalhadores ao partido conservador foi grande e, no final da década, a falha em cooperar com o governo trabalhista acarretou intensa onda de greves, contribuindo para levar ao poder uma nova vertente do partido conservador, liderada por Margareth Thatcher (ibidem).

Uma vez no governo, Thatcher colocou em ação pontos da agenda da New Right, com forte ênfase em uma política monetária apertada para vencer a inflação. O resultado foi uma grave recessão que a tornou um dos mais impopulares primeiros-ministros da história. Entretanto, eventos como a Guerra das Malvinas, em 1982, e a greve dos mineiros em 1984/1985, deram ao governo o apoio para implementar outros pontos da agenda (ibidem).

Thatcher removeu as restrições aos movimentos financeiros, dando grandes oportunidades às empresas britânicas. Forte ênfase foi dada à desregulamentação do mercado de trabalho e à redução dos custos trabalhistas. Houve redução do prazo e do valor do seguro-desemprego ${ }^{6}$ e das taxas de reposição relativas ao auxílio-doença e aos acidentes de trabalho. Houve também enfraquecimento dos sindicatos e significativa modificação nas políticas de emprego, com o endurecimento das regras para os desempregados procurarem e aceitarem um emprego ${ }^{7}$.

A estratégia britânica sumariza traços de uma estratégia compartilhada por Estados Unidos, Austrália e Nova Zelândia, que também privilegiaram a redução dos custos trabalhistas e o enfraquecimento dos sindicatos. Houve queda nos benefícios de aposentadoria, no segurodesemprego e em outros benefícios. A aposta era que a menor regulamentação favoreceria a criação de novos empregos. De fato, esta estratégia produziu elevação na demanda por trabalho. A partir dos anos 1980, o crescimento do emprego foi três vezes maior neste cluster e as taxas de desemprego atingiram os níveis mais baixos entre os países desenvolvidos (Azeredo, 1998; Kerstenetzky, 2012).

No entanto, as medidas resultaram também em deterioração das condições sociais e em aumento da desigualdade. A redução dos salários e dos benefícios ampliou o número de trabalhadores e de desempregados situados abaixo da linha de pobreza. Houve crescimento do número de pessoas sujeitas a empregos precários e de baixa remuneração ${ }^{8}$. Nos Estados Unidos, programas de assistência social foram elimina- 
dos, em troca de obrigar os pobres a aceitar um emprego qualquer. Houve aumento do número de trabalhadores sem acesso à previdência, aos planos de saúde e ao seguro-desemprego. Destacam-se também as baixas chances de ascensão social e a deterioração da situação de grupos mais vulneráveis. A incidência de pobreza entre mães solteiras chegou a 50\% (Kerstenetzky, 2012:109).

Apesar das mudanças, também nesse cluster o Welfare State encontrou resiliência. Pierson (2007) mostra como Reagan, após fazer cortes em programas de auxílio aos pobres e crianças dependentes, encontrou dificuldades em ir adiante e teve de recuar. Também no Reino Unido, a despeito da concentração de poder pelo primeiro-ministro, muito do Welfare State permaneceu intacto. O Estado de Bem-Estar Social criou lealdades em torno de suas políticas, tornando difícil fazer cortes em benefícios valorizados pelos cidadãos (ibidem).

A variante liberal ficou restrita a alguns países, sendo que grande parte dos países europeus optou por preservar e/ou adaptar as práticas anteriores. Um segundo grupo, composto por países como Suécia e Dinamarca, era caracterizado por um Estado de Bem-Estar Social universal marcado por alto grau de desmercantilização (decommodification; Esping-Andersen, 1990). Na Dinamarca, o seguro-desemprego podia durar 260 semanas, em um valor em torno de $70 \%$ a $80 \%$ do salário prévio. Em ambos os países, havia sólidos arranjos corporativistas.

Em face das dificuldades, os suecos responderam com a preservação da política característica das décadas anteriores ${ }^{9}$. Subsídios foram concedidos para estimular o emprego e a qualificação dos trabalhadores foi reforçada (Weishaupt, 2011). Outro pilar foi o recurso aos mecanismos corporativistas de negociação salarial, que contribuíram para menores pressões salariais. A Suécia recorreu também à intensa expansão do emprego público. O modelo sueco demonstrou grande resiliência, sendo considerado um bastião de resistência às novas tendências. Na contramão do que ocorria em outros países, as taxas de desemprego não ultrapassaram os $3 \%$ e o desemprego de longo prazo era praticamente inexistente.

Entretanto, essas políticas não resistiram ao acirramento da crise no início dos anos 1990, agravada pelas dificuldades na vizinha Finlândia. Em face da desaceleração econômica, o aumento do déficit público provocou especulação contra a coroa e a fuga de capitais. Entre 1991 e 1993, a Suécia obteve taxas negativas de crescimento e queda na produ- 
tividade. Em face do baixo crescimento da oferta de emprego, a efetividade das políticas de emprego reduziu-se significativamente. O desemprego passou de $2 \%$, no final dos anos 1980, para $9 \%$ em meados dos anos 1990 (Becker, 2011:48). Segundo Steinmo (2013:93), a crise refletiu também excessos do modelo. As alíquotas de impostos estavam excessivamente elevadas, desestimulando o trabalho, enquanto a generosidade excessiva de alguns benefícios indicavam casos de abuso.

A crise abriu a possibilidade de mudanças, favorecidas pela presença de um partido de centro-direita no poder. Benefícios sociais foram cortados para enfrentar o déficit, implicando cortes no seguro-desemprego, no auxílio-doença e nas aposentadorias (Lindgreen, 2011:51). A proteção ao emprego passou por leve relaxamento. Houve também reformas no sistema tributário e no sistema de seguridade social, feitas com o objetivo de combinar igualdade e sustentabilidade fiscal. Segundo Steinmo (2013), foi essencial o alto grau de insulamento da elite política, criando capacidade para implementar reformas difíceis.

Um grande recuo marcou as práticas mais coordenadas de negociação salarial. Após o abandono da negociação centralizada, em 1983, seguiram-se anos de tensão entre empresários e sindicatos, resultando, em 1995, na mais descoordenada rodada de negociação salarial desde a Segunda Guerra Mundial (Lindgreen, 2011:55). Os resultados foram frustrantes, dada a reivindicação dos sindicatos por reajustes muito altos. O evento mostrou que, em face da força dos sindicatos, práticas coordenadas de negociação eram fundamentais para garantir paz e estabilidade nas relações de trabalho.

A partir dos anos 1990 houve a recuperação da economia, marcada pelo crescimento da produtividade e pela queda do desemprego, que atingiu, ao final da década, níveis entre $4 \%$ e $6 \%$. O partido socialdemocrata, de volta ao poder, reverteu alguns cortes nos benefícios feitos, além de retomar o estilo mais negociado de implementação das políticas. A ênfase na austeridade foi mantida.

A Dinamarca também respondeu à crise com políticas keynesianas, mas o aumento do déficit público e os desequilíbrios no balanço de pagamentos motivaram o seu abandono. O governo passou então a adotar direções mais monetaristas, privilegiando a busca pela competitividade. O desemprego se elevou e manteve-se alto ao longo da década de 1980. Diagnósticos destacaram, entre as principais dificuldades, a 
baixa taxa de participação no mercado de trabalho e a baixa qualificação da força de trabalho (Andersen e Svarer, 2007).

Enquanto a Suécia manteve-se firme à ideia de preservar o pleno emprego, a Dinamarca privilegiou a proteção aos trabalhadores em dificuldades. Em 1979, 84\% dos gastos com políticas de emprego era destinado à assistência aos desempregados (Weishaupt, 2011:112). Ao longo dos anos 1980, no entanto, a Dinamarca fortaleceu as práticas de qualificação e rotatividade no emprego. Medidas foram adotadas para flexibilizar a negociação salarial e o governo obteve dos sindicatos menores demandas por reajustes salariais. As reformas implantadas no início dos anos 1990, exploradas na seção intitulada Enfrentando o Trade off: O Modelo Social-Democrata e a Flexiseguridade (flexicurity), foram acompanhadas por dez anos de crescimento do emprego (Mailand, 2011:93).

Em síntese, tanto a Dinamarca como a Suécia sofreram os impactos das mudanças internacionais e os impactos sobre o Welfare State. As dificuldades foram agravadas pela desindustrialização, que entre 1970 e 2005 levou à queda de 40\% dos empregos industriais (Einhorn e Logue, 2010). O novo contexto apontava as dificuldades em preservar os benefícios: na ausência de reformas, poder-se-ia comprometer a viabilidade do Welfare State. Assim, ampliaram-se as pressões para melhorar a eficiência, estimular o trabalho e reduzir os gastos, levando os governos a apertar os critérios para a concessão dos benefícios. As mudanças, como se argumenta mais adiante, foram feitas de forma a preservar a ênfase igualitária deste Estado de bem-estar social.

Uma terceira variante de respostas foi adotada por alguns países da Europa continental, incluindo França e Alemanha. Nestes países, a força dos sindicatos e a estrutura do Welfare State contribuíram para a preservação de altos salários e benefícios aos trabalhadores segurados ${ }^{10}$. No entanto, a manutenção destas práticas, tornando altos os custos trabalhistas e rígidas as demissões, desestimulava a contratação. Enquanto os insiders eram protegidos, os outsiders, principalmente jovens, mulheres e trabalhadores de baixa qualificação, enfrentavam dificuldades de inserção no mercado de trabalho. Como resultado, as taxas de desemprego permaneceram altas, ultrapassando $10 \%$.

Um fator a explicar a resistência às reformas é a estrutura do Estado de Bem-Estar Social desenvolvido nesses países, centrado em benefícios seletivos determinados a partir da estrutura ocupacional. Nesse regi- 
me, os benefícios foram inicialmente concedidos aos operários industriais como forma de ampliar o apoio político. Consolidou-se um regime em que os benefícios dependiam de contribuições ligadas ao emprego e em que os programas de seguridade eram separados por categorias. Os beneficiários, bem organizados, exerciam resistência aos cortes. Outro fator a explicar a resiliência é a tradição de proteção social baseada na família tradicional, em que a preocupação central é salvaguardar o emprego dos homens chefes de família (EspingAndersen, 1990).

Em síntese, a resposta inicial baseou-se na proteção aos trabalhadores segurados. Outras políticas incluíram a redução das horas de trabalho e o incentivo à aposentadoria precoce de trabalhadores desempregados a longo tempo. Essas medidas, além de insuficientes, provocaram pressões sobre o déficit público. A baixa participação da mulher no mercado de trabalho e as dificuldades do Welfare State em lidar com estruturas de famílias não tradicionais colocaram dificuldades adicionais (Esping-Andersen, 2007:54).

Após anos de alto desemprego, reformas foram adotadas na direção de flexibilizar parte da legislação, sendo introduzida a possibilidade de contratação por tempo determinado e por período parcial, principalmente nas pequenas empresas. Outra mudança foi a redução dos encargos trabalhistas e nos benefícios do seguro-desemprego ${ }^{11}$. Na Alemanha, as políticas de mercado de trabalho ativas foram reforçadas, emulando práticas adotadas no Reino Unido (Seeleib-Kaiser e Fleckenstein, 2007) ${ }^{12}$. Em síntese, embora a regulação do mercado de trabalho e a proteção aos trabalhadores continuassem altas, os países continentais passaram a adotar reformas para reduzir a rigidez do mercado de trabalho. Os resultados foram positivos e o emprego passou a crescer.

As respostas acima, que compartilham o desafio de lidar com os novos constrangimentos, diferem amplamente. A rota liberal individualizou os riscos, focando no "estímulo" ao trabalho e ampliando as desigualdades. A rota continental privilegiou a proteção ao trabalhador segurado e ampliou a divisão insiders-outsiders, passando, aos poucos, a introduzir medidas que provessem maior flexibilidade. A rota escandinava fez ajustes e recuos pontuais, socializando os riscos e reformulando as políticas de emprego (Kerstenetzky, 2012). A seção seguinte sintetiza o papel dos constrangimentos, abordando os principais fato- 
res capazes de pressionar por mudanças no Estado de Bem-Estar Social.

\section{CONSTRANGIMENTOS, INSTITUIÇÕES E RESPOSTAS}

Um passo importante é sistematizar o papel dos constrangimentos que poderiam implicar recuo do Welfare State, avaliando também se houve recuo do Estado de Bem-Estar Social e em que grau. Há, inicialmente, os constrangimentos macroeconômicos que acompanham as mudanças no regime cambial e a desregulamentação dos movimentos financeiros. A nova ordem econômica requer disciplina fiscal e controle da inflação, reduzindo a capacidade dos governos perseguirem políticas de pleno emprego. Este desafio fiscal é agravado pelas mudanças na estrutura das famílias e pelo envelhecimento da população, que se reflete na redução da relação contribuintes/aposentados ${ }^{13}$.

Um fator muito destacado pela literatura, particularmente por análises que defendem a convergência em direção a um modelo liberal, são as mudanças que teriam tornado o capital mais móvel, incluindo as novas regras internacionais e as novas tecnologias de comunicação. Segundo esta tese, batizada de "tese da globalização", um contexto marcado por maior concorrência e facilidade de deslocamento pressionaria os governos a promover um ambiente mais favorável ao capital, reduzindo encargos e a proteção ao trabalho e levando a um recuo do Welfare State.

Outra fonte de pressão estaria ligada à União Europeia (UE), que teria implicado maior disciplina fiscal e a intensificação dos fluxos de mercadorias, investimentos e recursos entre os países membros. Acreditava-se também que regulações da UE poderiam levar a efeitos homogeneizadores na relação capital-trabalho. Um quinto possível vetor de mudança viria de um processo cultural de individualização, acentuando a responsabilidade do indivíduo e contribuindo para reduzir a solidariedade em relação ao Welfare State (Becker, 2011). E em sexto lugar, há os impactos das mudanças no mundo do trabalho, relacionados à perda de empregos industriais, à mudança na natureza dos empregos e à dificuldade de alcançar o pleno emprego.

Paul Pierson (2001) avalia o impacto potencial de cada um destes fatores. Uma de suas principais teses é o alto grau de resiliência do Welfare State, uma vez que lealdades consolidadas em torno do mesmo teriam tornado o custo de desmontá-lo alto demais (Pierson, 2007:147). Não obstante, ao abordar os fatores capazes de explicar recuos, Pierson 
(2001) encontra que o mais relevante teria sido a queda dos empregos industriais de maior produtividade. Schwartz (2001) encontra que a maior mobilidade financeira, apesar dos constrangimentos sobre a política macroeconômica, não seria fator relevante para explicar recuos no Welfare State. A principal fonte de constrangimentos viria do fator demográfico, a colocar pressões sobre os gastos em saúde e aposentadoria.

Um ponto fundamental para o argumento do presente artigo é analisar a chamada "tese da globalização". Há várias críticas a esta tese. Um primeiro ponto é que os principais Estados de bem-estar social desenvolveram-se em pequenas economias com enorme grau de abertura, sendo a maior exposição à competição acompanhada por mecanismos voltados a proteger a sociedade das flutuações no ciclo econômico (Katzenstein, 1985). Em outras palavras, a correlação entre abertura e gastos do Welfare State sempre foi elevada, havendo pouca base para argumentar que a intensificação da abertura iria forçá-lo a recuar.

Um segundo ponto argumenta que o investimento produtivo é relativamente fixo, beneficiando-se de externalidades locais, algumas relacionadas ao Welfare State. Um Welfare State generoso implica não apenas custos elevados, mas formas de beneficiar a economia (Hay e Wincott, 2012:71). Por um lado, tende a favorecer a geração de trabalhadores saudáveis e educados, com efeitos positivos sobre a participação no mercado de trabalho. A participação dos trabalhadores nas decisões das empresas e a maior proteção ao emprego, por sua vez, tendem a estimular o investimento em qualificação e a inovação no chão da fábrica (idem:115). Como concluem Hay e Wincott, o "Welfare State tende a ter papel-chave na consolidação de relações industriais cooperativas que favorecem o investimento em capital físico e humano" (idem:129; tradução livre).

Em terceiro lugar, o Welfare State, ao proteger os indivíduos das flutuações econômicas, tende a ter efeitos sobre o consumo, positivamente correlacionado com o crescimento econômico (Becker e Kersbergen, 2011:187). Um quarto elemento crítico está relacionado ao fato de que o Welfare State tende a reduzir os custos de transação e a favorecer a confiança e a cooperação. Quinto, um Welfare State mais generoso, ao reduzir a desigualdade, tende a contribuir para menores taxas de criminalidade e para a redução dos custos com encarceramento e segurança, assim como dos efeitos negativos do crime sobre o capital humano ${ }^{14}$. 
Um ponto central é que os países com Estado de Bem-Estar Social generosos tendem a competir não por baixos custos do trabalho, mas por qualidade e inovação (Hay e Wincott, 2012:115). Neste sentido, é interessante notar que as principais dificuldades econômicas vêm sendo enfrentadas pelos países europeus com menor capacidade de inovar, os mesmos que vêm sofrendo maiores pressões para recuar o Estado de bem-estar social.

O argumento contrário à tese da globalização pode ser respaldado também em bases empíricas. A maior integração econômica vem ocorrendo há algumas décadas, sem que isto tenha levado a um fluxo de empresas abandonando os países europeus mais desenvolvidos em direção a economias desreguladas. As principais empresas continuam baseadas em seus países de origem, que apresentam resultados muito consistentes em termos de competitividade e crescimento (ver a seção intitulada Enfrentando os Desafios: As Lições da Resposta Escandinava, deste artigo).

Recusar a tese da globalização não implica, no entanto, que os constrangimentos não sejam significativos e que não haja recuos do Welfare State. Os constrangimentos macroeconômicos e fiscais são significativos, agravados pelas mudanças demográficas e pelas novas tendências do mundo do trabalho. A União Europeia coloca ainda constrangimentos suplementares, devido também a certas decisões da Corte Europeia de Justiça, que podem comprometer a capacidade de alguns países regularem o capital (Smith, 2011:169). Em relação à tese da individualização, surveys mostram que apesar de haver certo fortalecimento de teses individualistas, há inúmeras diferenças entre os países, assim como apoio expressivo para o Welfare State (Becker, 2011:24).

Uma questão essencial é se houve um recuo do Welfare State e em que fica assim: grau ele ocorreu. Kerstenetzky (2012:cap. 4) argumenta que o recuo foi relativo, com retração em algumas áreas acompanhado de resiliência em outras. Hay e Wincott (2012) seguem vários indicadores na tentativa de concluir algo sobre o recuo dos Estados de bem-estar social. Ao observar o comportamento dos gastos sociais em porcentagem do Produto Interno Bruto (PIB), os autores notam que há uma inflexão nos anos 1980, marcada pela desaceleração do crescimento e depois pela estabilização dos gastos. Esta estabilização, no entanto, implica redução na generosidade dos benefícios, o que se explica pelos custos crescentes que tendem a acompanhar o envelhecimento da po- 
pulação e os mais complexos serviços de saúde. Ou seja, se o grau de generosidade continuasse o mesmo, os gastos em relação ao PIB tenderiam a crescer (ibidem:100 e 177).

Também Becker (2011:34-35) encontra uma tendência geral à redução dos benefícios e a um menor grau de decommodification dos Welfare States. Nas suas palavras, alguns Welfare States tornam-se menos inseridos (embedded), tendendo a reduzir o grau de cobertura e o valor dos benefícios. A menor generosidade traduziu-se na redução dos benefícios do seguro-desemprego, do auxílio-doença e das pensões, mas também em menores graus de proteção ao emprego, com o crescimento de empregos temporários e mal pagos.

Apesar do recuo, o impacto distributivo do Welfare State continua alto, contribuindo para reduzir o coeficiente de Gini em proporções que variam de $44 \%$ na Dinamarca e na Suécia a 17\% nos EUA (Kerstenetzky, 2012:77). Além disto, não se encontra convergência em direção a um cluster. Segundo Hay e Wincott (2012:103), o desvio-padrão entre os grupos de países continua o mesmo: o regime nórdico continua o mais generoso, seguido pela Europa continental e com grande diferença em relação aos países liberais. Isto é ilustrado pelos gastos em transferências e serviços sociais: em 2009, os países escandinavos gastavam algo como $37 \%$ do PIB, seguidos pelo cluster continental (30\%) e pelo cluster liberal (25\%) (Hay e Wincott, 2012:182). Em algumas áreas, como seguro-desemprego e auxílio-doença, as diferenças se acentuaram.

Assim, outra conclusão essencial é que a relação entre as mudanças na economia e as modificações no Welfare State é mediada pelas instituições nacionais. O Welfare State representou um processo de construção econômica, moral e política, introduzindo direitos que afetam diversos segmentos sociais. Isto ajuda a entender não apenas a dificuldade de desmontá-lo, mas a relevância do tipo de Welfare State e da capacidade de amarrar lealdades. Algumas reformas foram mais fáceis nos países que compartilhavam o Estado de Bem-Estar Social liberal, centrado no grupo mais carente e com maiores dificuldades de mobilizar apoio político. O modelo continental mostrou-se mais resistente a reformas que afetassem diretamente os trabalhadores sindicalizados. Enfim, o modelo social-democrata tem conseguido negociar melhor as reformas consideradas necessárias. A capacidade de incorporar a classe média, fazendo-a se beneficiar das políticas, constitui fator decisivo para o apoio ao regime (Kerstenetzky, 2012:118-134). 
Em síntese, os novos constrangimentos implicaram recuo e reformulações em certas políticas, mas de forma alguma convergência. Os clusters continuaram bem delineados. Nos países liberais, consolidou-se maior segmentação nos programas de proteção, com os serviços públicos oferecendo proteção básica e os mais afortunados tendendo a recorrer ao setor privado ${ }^{15}$. Este regime tem apostado nas deduções fiscais para estimular serviços privados de saúde e previdência, mas as isenções tendem a se concentrar nos grupos de alta renda (ibidem:111).

No regime continental ou conservador, que apresenta grau intermediário de decommodification, vem ocorrendo crescimento da aposentadoria privada e de serviços privados de saúde, medidas que contribuem para ampliar o dualismo entre insiders e outsiders. Entre as principais dificuldades, encontram-se as consequências da familiarização do bem-estar e a incapacidade de responder aos novos riscos ${ }^{16}$. Enfim, os países escandinavos vêm demonstrando maior capacidade de implementar mudanças e de preservar os aspectos igualitários do Welfare State. A próxima seção explora a resposta da Dinamarca ao trade off emprego/proteção, considerada paradigmática no enfrentamento dos desafios do mundo do trabalho. A seguinte, explora o papel do corporativismo e de outros fatores para a capacidade de Dinamarca e Suécia viabilizarem as reformas.

\section{ENFRENTANDO O TRADE OFF: O MODELO SOCIAL-DEMOCRATA E A FLEXISEGURIDADE}

Até os anos 1970, o modelo dinamarquês apresentou baixas taxas de desemprego e generosos benefícios sociais. O seguro-desemprego durava cinco anos e podia ser renovado pela participação em programas de treinamento. A crise alterou o quadro, com grande crescimento do desemprego de longo prazo. A constatação de que havia, ao mesmo tempo, grande número de desempregados e falta de trabalhadores em certos setores foi decisiva para a adoção de mudanças em direção a uma nova abordagem. Esta abordagem ilustra pontos importantes para o objetivo do artigo. Primeiro, por se constituir em alternativa ao trade off emprego/seguridade; segundo, por exemplificar a adoção de ajustes necessários para a preservação do Estado de Bem-Estar Social.

O modelo dinamarquês é caracterizado pela grande proporção de pequenas empresas e pelo alto grau de abertura ao exterior. A participação das pequenas empresas, somada ao amplo histórico de negociação, 
contribuiu para gerar maior flexibilidade nas relações de trabalho. Os empregadores têm autonomia para variar as horas de trabalho, a jornada de trabalho e as funções desempenhadas pelos trabalhadores. Esta flexibilidade, no entanto, é acompanhada pela participação nas negociações coletivas, que definem padrões que devem ser seguidos, incluindo o valor do salário mínimo, a igualdade de rendimentos entre homens e mulheres e a duração da jornada de trabalho ${ }^{17}$. As empresas, por sua vez, têm flexibilidade na forma de cumpri-los. No caso da jornada de trabalho, as firmas podiam distribuir as horas entre os dias da semana e mesmo entre semanas, flexibilidade que, após 1995, foi estendida para alguns meses (Einhorn e Logue, 2010).

Apesar da flexibilidade e do baixo tempo médio de permanência no emprego, há ampla propensão das firmas a investir em treinamento ${ }^{18}$. Os trabalhadores têm conhecimento das várias etapas de produção, o que contribui para a maior flexibilidade (Mailand, 2011:81). O regime é também marcado por elevado grau de proteção social: a duração do seguro-desemprego é alta, os critérios de elegibilidade generosos e a taxa de reposição, principalmente para os grupos de baixa renda, elevados (Becker, 2011:184). Esta combinação entre flexibilidade e seguridade social levou à cunhagem do termo flexiseguridade, que se tornou central no direcionamento das políticas de emprego na Europa.

A flexiseguridade, no entanto, mostrou-se inicialmente incapaz de deter a escalada do desemprego. O diagnóstico apontou como principais dificuldades a baixa qualificação da força de trabalho e a grande proporção de pessoas dependentes dos benefícios sociais. A mudança mais significativa veio com a introdução de práticas de ativação e a adoção de um enfoque que procurava, ao mesmo tempo, incentivar e pressionar os indivíduos a se inserirem no mercado de trabalho (Andersen e Svarer, 2007). Um pilar foi o aperto dos critérios de concessão de seguro-desemprego: o prazo máximo de recebimento do seguro foi reduzido, com a exigência de participação, após o primeiro ano, em programas de capacitação e em outras atividades. Houve também modificação nos critérios para a renovação do seguro, que passou a exigir nova experiência de emprego. Embora as condições tenham se tornado mais rígidas, os valores continuaram generosos. A duração do seguro-desemprego era de 48 meses, com taxa média de reposição de $70 \%$, chegando a $90 \%$ para as faixas de mais baixa renda. A participação dos trabalhadores foi decisiva para a preservação dos altos índices de seguridade (Weishaupt, 2011). 
Houve também reforço das políticas ativas de mercado de trabalho, cujo gasto em proporção do PIB passou de 1,1\%, em 1986/1990, para 1,8\% em 1994/1997. O sistema público de emprego foi reformulado, com o fortalecimento dos serviços de orientação, intermediação e treinamento de mão de obra. Na redefinição das políticas de emprego, foram utilizadas várias técnicas ligadas à nova administração pública, incluindo o gerenciamento por objetivos, a participação do setor privado em programas de treinamento e oferta de emprego temporário e a descentralização das tarefas (Borges e Guimarães, 2011). Medidas foram também adotadas para favorecer o emprego temporário, muito regulado até os anos 1990, e para estimular o trabalho, incluindo a redução dos impostos em faixas mais altas de renda.

Um papel essencial foi desempenhado pelo reforço das políticas de treinamento, fundamentais para manter a alta produtividade e ajudar o desempregado a conseguir um emprego. Nessa política, a Dinamarca conta com órgãos tripartites, em que trabalhadores e empresários participam na definição dos gastos, nas fontes de financiamento e no balanceamento dos programas. Licenças foram concedidas para favorecer a participação dos trabalhadores: cada trabalhador com mais de dois meses no emprego passava a ter direito a duas semanas de treinamento financiadas pelo fundo tripartite. Os empresários canalizavam certa quantia por trabalhador para o financiamento dos programas (Mailand, 2011:85).

A partir da adoção do novo enfoque, mas também refletindo a recuperação da economia, o desemprego passou a cair, atingindo 5,5\% em 1998 e permanecendo baixo por grande parte da década seguinte. Embora parte do resultado seja creditada ao encaminhamento de pessoas para programas integrais de escolarização e capacitação (Daguerre, 2007), há evidências de redução no tempo médio de desemprego, de melhoria na taxa de saída do desemprego para o emprego e de redução na taxa de dependência (Andersen e Svarer, 2007).

O enfoque dinamarquês tende a ser criticado por se considerar que a ativação transfere o fardo para o indivíduo. É também criticado por ser considerado parte de uma estratégia centrada na redução dos direitos e nos interesses do capital (Daguerre, 2007). Estas críticas têm seu lado de verdade, uma vez que na raiz das mudanças estão as dificuldades do sistema capitalista. O argumento aqui defendido é que, uma vez que os países individualmente têm pouco controle sobre certas variá- 
veis, a reformulação deve ser vista como um passo para enfrentar os novos constrangimentos e preservar a ênfase igualitária do modelo.

Andersen e Svarer (2007) levantam uma questão esclarecedora: "por que não simplesmente reduzir os benefícios, forçando as pessoas a procurar um posto de trabalho?". Segundo os autores, tal posição, ao ferir a percepção de que é dever do Estado socorrer os necessitados, não seria tolerada. Não obstante, e em face dos constrangimentos, torna-se legítimo pedir para que os indivíduos trabalhem e contribuam para sustentar o Estado de bem-estar social. É neste sentido que se pode falar de redefinição do pacto: o Estado continua a ter o dever de assistir os indivíduos sem trabalho, mas estes devem fazer a sua parte para conseguir um emprego, contando com os serviços viabilizados pela política de emprego.

De forma similar, a combinação entre flexibilidade, ativação, seguridade e reforço das políticas de emprego implica que o importante é garantir proteção e oportunidades de emprego, e não segurança em um emprego específico, algo difícil em face das novas configurações da economia. O arranjo anterior não pode mais ser preservado, mas é fundamental que o Estado continue a proteger os indivíduos em dificuldades. Os benefícios mantêm a renda em momentos de necessidade, enquanto os serviços de treinamento, reciclagem e colocação ampliam as chances de se conseguir um emprego.

Paralelamente à experiência dinamarquesa, foi amadurecendo um novo enfoque para a política de emprego europeia. No início dos anos 1990, a Organização para Cooperação e Desenvolvimento Econômico (OCDE) fez um estudo que, influenciado pelos resultados alcançados por EUA e Reino Unido, defendia medidas que flexibilizassem o mercado de trabalho, reduzissem os encargos e endurecessem os critérios de elegibilidade para os benefícios (Weishaupt, 2011).

Em contraponto, ocorreram as primeiras iniciativas da União Europeia na direção de empreender reflexões que guiassem a política para os países membros. Embora compartilhando a necessidade de reduzir os custos do trabalho e estimular a busca por emprego, a abordagem abraçada pela UE enfatizava o papel dos governos em auxiliar os indivíduos, principalmente os mais vulneráveis, a obter um emprego. Em um influente documento de 1994, o Conselho Europeu destacava a necessidade de promover um crescimento mais intensivo em trabalho e de contar com a participação de empresários e trabalhadores no dese- 
nho e na implementação das políticas (Weishaupt, 2011). Na Estratégia de Emprego Europeia definida para o período 1997-2002, incorporaram-se direções como a adoção relativamente imediata de medidas de treinamento e de empregabilidade para jovens e desempregados de longo prazo; a necessidade de tornar o mercado mais flexível; a maior participação de empresários e trabalhadores; o fortalecimento de creches e serviços de cuidados e a redução das desigualdades entre homens e mulheres.

Em síntese, a estratégia europeia incorporou muitos traços da via dinamarquesa, a expressão, em âmbito supranacional, de práticas voltadas a enfrentar os novos desafios sem abandonar princípios e valores que marcaram a construção dos Estados de bem-estar social. Após a crise iniciada em 2007/2008, no entanto, a possibilidade de uma política de emprego europeia foi atropelada pelas dificuldades imediatas e pela vulnerabilidade de alguns países, cuja situação dramática implicou a adoção de um programa macroeconômico radical e de medidas de desregulamentação da economia. Nos países europeus mais desenvolvidos, muitas direções da flexiseguridade foram conservadas, enquanto outros ajustes foram adotados para enfrentar os aspectos mais urgentes da crise.

\section{ENFRENTANDO OS DESAFIOS: AS LIÇÕES DA RESPOSTA ESCANDINAVA}

A resposta dada pelos países escandinavos mostra que as novas configurações da economia mundial não levam necessariamente a mudanças em direção a um modelo liberal. Não obstante os constrangimentos, Suécia e Dinamarca adaptaram os respectivos modelos sem abrir mão dos princípios igualitários e de solidariedade inerentes ao Estado de Bem-Estar Social. O objetivo desta seção é apresentar aspectos das respectivas respostas, destacando fatores que ajudam a explicar a direção e os resultados.

Entre as mudanças, encontra-se a reforma nos sistemas de previdência. Suécia e Dinamarca contavam com sistemas universais e generosos de previdência, pouco dependentes da participação no mercado de trabalho. Estes sistemas passaram a sofrer pressões em decorrência das mudanças demográficas. Como resposta, ambos os países ampliaram a idade mínima de aposentadoria e introduziram planos de contribuição individual, a complementar o programa público universal. Na Suécia, a reforma preservou um padrão de vida decente para 
pessoas em idade de aposentadoria, independente da história de trabalho anterior. Mas pessoas nascidas após 1954 teriam um esquema de contribuição definida similar a um sistema privado. A reforma introduziu elementos de equilíbrio fiscal, uma vez que os benefícios da pensão básica estariam atrelados às contribuições correntes e, portanto, ao crescimento econômico e aos salários (Steinmo, 2013:96) ${ }^{19}$.

Já a Dinamarca optou por um sistema mais plano, com altas taxas de reposição para os trabalhadores menos qualificados e um fundo suplementar para os trabalhadores melhor remunerados. Medidas ulteriores estenderam a aposentadoria por ocupação para grande parte dos trabalhadores, visando complementar o sistema básico (Mailand, 2011:82). A contribuição suplementar, incidente sobre trabalhadores e empregadores, é relativamente baixa e não compromete a competitividade, além de contribuir para o aumento da taxa de poupança (Einhorn e Logue, 2010).

As reformas na previdência, assim como a expansão de serviços privados de saúde e a introdução de práticas ligadas à nova administração pública, vêm sendo realizadas sem comprometer a ênfase igualitária desse tipo de Welfare State. Ambos os países têm preservado serviços universais de saúde com inexistência de "mecanismos de verificação de carência". As pensões e os serviços de assistência continuam generosos, contribuindo para as baixas taxas de pobreza entre os idosos. A taxa de reposição para os desempregados é elevada, há baixa diferenciação entre os salários e é baixa a desigualdade entre homens e mulheres. Além disto, as taxas de desemprego de longo prazo e a proporção de trabalhadores que recebem baixos salários é bem inferior à média europeia (Becker e Kersbergen, 2011).

Tudo isto reflete nos menores índices de desigualdade e pobreza. O índice de Gini é um terço menor na Suécia e na Dinamarca do que na média de outros países europeus e $40 \%$ inferior ao dos EUA (Einhorn e Logue, 2010 $)^{20}$. As taxas de pobreza são bem inferiores às verificadas em outros países europeus (Becker e Kersbergen, 2011:182). Além disto, o cluster escandinavo apresenta as maiores taxas de mobilidade social: a probabilidade de pessoas nascidas no quintil inferior ascenderem é três vezes superior na Dinamarca em comparação com os EUA (Kerstenetzky, 2012:123).

Entre os fatores decisivos para a preservação de Welfare States generosos encontram-se os altos níveis de competitividade. Em 2007, 
Dinamarca e Suécia encontravam-se nas cinco primeiras posições em índices internacionais de competitividade (Einhorn e Logue, 2010). O ponto, como bem observado por Becker e Kersbergen (2011:187), é que os países nórdicos alcançam altos índices de competitividade apesar de adotarem várias das práticas criticadas pela teoria neoclássica, incluindo impostos altos, alta proteção no emprego (exceto Dinamarca), baixa desigualdade de salários e setor público inchado. Isto se explica pelos bons resultados em termos de ambiente de negócios e inovação. A Suécia gasta $4 \%$ do PIB em pesquisa e desenvolvimento (P\&D), enquanto na Dinamarca grande parte da inovação se dá no processo do trabalho, favorecida pela alta qualidade dos trabalhadores. Em indicadores de condições para inovação, incluindo infraestrutura, esforço ao nível das firmas e resultados em termos de know how, os dois países estavam entre os primeiros na Europa (ibidem:190). Na qualidade das instituições de educação, perdiam apenas para os Estados Unidos.

Outro fator essencial são as políticas igualitárias de gênero e a alta participação feminina no mercado de trabalho. Desde cedo, Suécia e Dinamarca vêm promovendo iniciativas voltadas à conciliação entre a família e o trabalho, incluindo a oferta de creches, generosas licenças-maternidade e paternidade e um sistema de tributação em que uma família com dois provedores tende a pagar relativamente menos impostos.

Merece especial ênfase a oferta de serviços sociais de cuidado às crianças, estando disponível para 50\% da população (ibidem:183). A expansão destes serviços, ao elevar os custos do Welfare State e os impostos, pressiona a mulher a entrar no mercado de trabalho, ao mesmo tempo que amplia a oferta de empregos. Deve-se destacar que as creches são de tempo integral, contam com professores especializados e contribuem para a baixa desigualdade educacional. São serviços que atraem a classe média/alta e contribuem para legitimar a alta carga tributária (Weishaupt, 2011).

O resultado são maiores taxas de natalidade e a alta participação feminina no mercado de trabalho ${ }^{21}$. Como consequência, a taxa de participação da população entre 15 e 64 anos teria alcançado $73,9 \%$ na Suécia e 75,5\% na Dinamarca, 10 pontos percentuais acima da média europeia e 3 pontos acima do Reino Unido e dos Estados Unidos (Einhorn e Logue, 2010:21). Além disto, quando duas pessoas trabalham, o risco de pobreza das crianças reduz significativamente. 
A capacidade de reformar deveu-se à participação de empresários e trabalhadores. Ambos os países contam com arranjos corporativistas para a definição e a implementação das políticas, havendo várias instâncias de negociação entre capital e trabalho (Mailand, 2011). A filiação aos sindicatos é alta, sendo que $79 \%$ dos trabalhadores na Suécia e $74 \%$ na Dinamarca estavam filiados a sindicatos, contra, por exemplo, $10 \%$ na França e 25\% na Alemanha (Becker, 2011:23). A representatividade dos sindicatos e das associações empresariais é essencial para o estilo consensual das reformas. Além disto, os parceiros sociais (empresários e trabalhadores) são fundamentais para o sucesso das políticas de emprego e para que a flexiseguridade produza bons resultados.

Como destaca Martin (2004), a participação dos empresários muito contribui para o sucesso das políticas de emprego, sendo essencial para a disponibilização de vagas, para a antecipação das habilidades necessárias, para o desenho dos programas de treinamento e para a contratação de trabalhadores com deficiência. Martin (idem) mostra que a participação dos empresários nas políticas ativas é muito superior na Dinamarca que na Grã-Bretanha (68\% a 40\%). No caso escandinavo, os empresários encaram a participação como parte de suas funções, o que é fruto de longa tradição de corporativismo e do legado de parceria.

A vigência de práticas institucionalizadas de participação foi parte essencial do processo de reformas. Especialistas foram convidados a realizar estudos abrangendo tópicos como reestruturação econômica e reformas do sistema de saúde e da previdência. Os estudos, ao iluminarem os desafios, contribuíram para o processo de negociação. Destacou-se também o enorme grau de realismo na condução das reformas. Propostas de isenção e de redução de impostos tendiam a ser acompanhadas por apresentação de alternativas de financiamento ou de corte nos gastos (Einhorn e Logue, 2010).

O estilo consensual de policy making não implica inexistência de conflitos. Há disputas árduas por reajuste de salários e outras fontes de conflito. Negociação não implica falta de conflito, mas disposição para resolvê-los e atingir algum grau de consenso (Becker e Kersbergen, 2011: 190). Nesta direção, sindicatos e associações mais abrangentes, indicando a preocupação com questões gerais, tendem a se mostrar mais sensíveis aos ajustes necessários (Olson, 1982; Einhorn e Logue, 2010). Destaca-se também o alto grau de capital social. Na média, um dina- 
marquês pertence a 3,1 organizações e um sueco a 3,2. O resultado tende a ser a maior preocupação com as questões gerais da sociedade e a defesa de certo patamar de direitos para todos os indivíduos.

Os desafios são muitos. O sucesso do modelo deve-se à sua capacidade de entregar serviços de alta qualidade. Assim, é fundamental que continue a produzir bons resultados em termos de competitividade e eficiência dos serviços. É também essencial que os sindicatos continuem fortes, condição para garantir o equilíbrio com os empresários e preservar os resultados sociais. Outros desafios podem vir da Corte Europeia de Justiça e de proibições a certas restrições à mobilidade de capital, medidas que podem afetar a negociação entre capital e trabalho (Smith, 2011).

Em síntese, destaca-se a grande capacidade desses países negociarem e gerirem as reformas. Os novos constrangimentos implicaram redução dos benefícios e do grau de decommodification. A desigualdade aumentou levemente, com o índice de Gini passando de 0,221 (em meados dos anos 1990) para 0,232 (em meados dos anos 2000) na Dinamarca, e de 0,211 para 0,234 na Suécia (Becker e Kersbergen, 2011:182). Conforme argumenta Lindgreen (2011:64), as reformas foram muitas e houve, de fato, redução dos benefícios. Mas a magnitude das mudanças foi pequena, de forma que soam muito mais como um ajuste do que como um recuo. Smith (2011:149) sintetiza muito bem o ponto, argumentando que esses países introduziram flexibilidade sem abandonar a proteção, tornaram pensões sustentáveis sem reduzir significativamente a renda dos que as recebem e ajustaram benefícios sem abandonar a ênfase na igualdade, solidariedade e universalidade. Portanto, o mais importante a explicar não é o recuo, mas a preservação de tantos traços. A resposta, como o artigo vem argumentando, relaciona-se ao conjunto de instituições inerentes a esses países, incluindo a organização do Estado de Bem-Estar Social, a consolidação de uma cultura nacional favorável à igualdade, a força dos sindicatos e o papel dos parceiros sociais.

\section{CONSIDERAÇÕES FINAIS}

O caso dos países escandinavos ilumina a relação entre conjuntura internacional, constrangimentos econômicos e Welfare State. A conciliação entre os imperativos do capitalismo e as políticas de solidariedade/distribuição não foi inviabilizada pelas novas configurações da ordem internacional, pelo menos em alguns países. O artigo ilumina o 
papel das instituições que fazem a mediação entre os constrangimentos econômicos e as políticas do Welfare State.

Os resultados foram favorecidos pelo corporativismo, pelas políticas de emprego e pelas medidas voltadas a viabilizar a participação da mulher no mercado de trabalho. Becker e Kersbergen (2011) perguntam se o modelo escandinavo pode ser emulado por outros países da Europa. Não se trata de copiar as instituições, mas de desenvolver confiança e um padrão discursivo para alcançar resultados considerados desejáveis. Na Dinamarca e na Suécia o corporativismo é resultado de longa tradição e continuidade, mas na Áustria foi construído em algumas décadas. É difícil, no entanto, imaginá-lo em países com forte tradição individualista, até porque a viabilização de sociedades igualitárias requer aumento de impostos e tende a sofrer a oposição dos mais ricos.

Por trás do novo quadro encontram-se as mudanças no mundo do trabalho. Tornou-se mais difícil atingir o pleno emprego, assim como garantir rendas elevadas independentemente da participação no mercado de trabalho. Tornou-se necessário reduzir os custos do emprego e aumentar a flexibilidade do contrato de trabalho, mas essas medidas foram conciliadas com a proteção ao trabalhador e com o fortalecimento das políticas de emprego.

Surgiram novos desafios para o Welfare State. O antigo estava muito centrado no trabalho formal e na proteção à velhice. O novo tem de lidar com o trabalho precário, com diferentes estruturas familiares e com os riscos de exclusão dos imigrantes e dos trabalhadores com baixa qualificação. Um grande desafio é reduzir o risco de pobreza entre os jovens e abrandar as dificuldades na primeira infância. Outro é ampliar as chances de mobilidade social. Por fim, há a necessidade de estimular o aumento da fertilidade. A adoção de medidas visando conciliar trabalho e família tende a ser parte da solução (Kerstenetzky, 2012:120-121; Esping-Andersen, 2007).

Cada regime tem seus desafios. No regime liberal, a residualização dos serviços foi forte, acompanhada por desigualdade e deterioração das condições sociais, o que pode agravar o déficit em termos de legitimidade e coesão social. Já o regime conservador foi marcado por mudanças nas relações de trabalho e nas políticas de emprego, indicativo de que a dependência da trajetória não é assim tão rígida e que novos desafios, práticas e ideias podem contribuir para reformulações nas es- 
tratégias (Weishaupt, 2011). Este regime enfrenta o crítico desafio de reformular um Welfare State que foi alicerçado em uma divisão do trabalho entre os gêneros que se modificou profundamente. Enfim, o regime escandinavo destaca-se pela maior capacidade de conciliar a resposta aos novos constrangimentos com a preservação de políticas igualitárias e universais. Enfrentam, naturalmente, significativos desafios, incluindo o imperativo de continuar oferecendo serviços de qualidade, essenciais para o apoio a um Welfare State financiado por impostos elevados (Weishaupt, 2011).

A crise iniciada em 2007/2008 trouxe novos desafios e apreensões. Alguns países europeus compartilharam a bolha imobiliária, enquanto outros sofreram com o contágio do sistema financeiro. Outros países, como os escandinavos, sofreram principalmente devido à queda do comércio internacional, que caiu muito mais abruptamente do que a produção. Na Suécia, em 2009, as exportações caíram 5 pontos percentuais em relação ao PIB e na Dinamarca a queda foi de 8 pontos percentuais. O resultado foi uma queda do PIB (em termos reais) de $5 \%$ na Suécia e 5,1\% na Dinamarca ${ }^{22}$. A Suécia recuperou-se rapidamente, beneficiando-se da situação financeira mais sólida e das lições da crise dos anos 1990. A capacidade de resposta foi amplamente elogiada (Steinmo, 2013:100). Já na Dinamarca, o PIB recuperou-se levemente em 2010 e 2011 e voltou a cair em 2012 e 2013. A intensidade da crise implicou novas dificuldades em ambos os países, incluindo novo aumento da desigualdade. É cedo para tirar conclusões, mas as evidências indicam um padrão de respostas similar ao verificado nas últimas décadas.

O principal impacto da crise vem sendo enfrentado pelos países do sul da Europa e pela Irlanda. A situação gravíssima levou a políticas de austeridade, cortes nos benefícios e flexibilização do mercado de trabalho. Hermann (2014) fala de convergência destes países na direção de um modelo mais liberal, mas não faz menção aos países europeus mais desenvolvidos, como Alemanha, França, Holanda e os países escandinavos. Estes, com maior capacidade de inovação e competição por qualidade, têm maiores graus de liberdade para calibrar os respectivos modelos.

O capitalismo, apesar do seu potencial em termos de expansão das condições materiais, tem suas contradições e fragilidades. A solidificação dos Estados de bem-estar social após a Segunda Guerra Mundial 
foi uma resposta a essas dificuldades, visando garantir condições básicas de vida para todos. A possibilidade de preservação do arranjo, no entanto, depende do bom desempenho econômico e está vulnerável às vicissitudes do capitalismo. Neste sentido, respostas que permitam conciliar bom desempenho econômico e alta proteção social devem ser encaradas como possível fonte de lições.

Como argumentado, os constrangimentos econômicos não implicam necessariamente a adoção de estratégias liberais. Quando o fazem, são parte de um arranjo político que beneficia certos interesses e produz desigualdade. Encontramos, em alguns países, configurações institucionais que se caracterizam pela valorização da participação e do diálogo. Consideram que a economia está inserida em um conjunto mais amplo de instituições e valores, entre eles os de direitos sociais e cidadania. Estas experiências mostram que há alternativas a um capitalismo mais desregulado e escravo das flutuações do mercado. Essas alternativas, mesmo difíceis de serem institucionalizadas, têm implicações para os países em desenvolvimento. Indicam que resultados promissores podem ser alcançados por sociedades que valorizem o diálogo e defendam um patamar básico de direitos e serviços. Mesmo estando muito distante da realidade desses países, apontam um rumo possível, com relevantes implicações políticas.

(Recebido para publicação em abril de 2014)

(Reapresentado em março de 2015)

(Aprovado para publicação em abril de 2015) 


\section{NOTAS}

1. O fordismo teve impacto revolucionário: em 1914, um carro Ford modelo T custava 1.950 dólares, valor que caiu para 200 dólares em 1929, impulsionando substancialmente o consumo.

2. Na Espanha, no início dos anos de 1950, havia um carro para cada 314 mil pessoas, enquanto na França havia um carro para cada 12 lares. Na França, em 1960, apenas uma em cada oito famílias possuía televisão.

3. Mesmo com certo revezamento no poder, o fortalecimento do Welfare State foi incorporado pelos partidos. Aspectos do discurso liberal foram abandonados (Gourevitch, 1986).

4. A desregulamentação das operações financeiras está relacionada à internacionalização dos bancos e à decisão de autorizar operações em dólares entre os países, levando à constituição do mercado de eurodólares. Nos anos 1970, o processo intensificou-se, buscando-se no sistema financeiro oportunidades de compensar a queda da taxa de lucro no setor produtivo (Arrighi, 2008).

5. As questões metodológicas ligadas à classificação dos regimes de Estados de BemEstar Social, bem tratadas por Hay e Wincott (2012) e por Kerstenetzky (2012), não afetam as conclusões principais do artigo.

6. O seguro-desemprego foi limitado a seis meses.

7. Segundo Weishaupt (2011), o Reino Unido ilustra um caso único na Europa de mudança de regime, dando origem a um WS liberal.

8. No Reino Unido, o índice de Gini passou de 0,27, em 1979, para 0,34 em 1999. Antes da introdução do salário mínimo, em 1999, alguns empregos pagavam menos de duas libras por hora (Daguerre, 2007).

9. Nos anos 1950, a Suécia consolidou um modelo que, fundado em políticas de treinamento e de recolocação de trabalhadores, promovia pleno emprego e aumento da produtividade em uma economia de altos salários (Weishaupt, 2011).

10. Na Alemanha, o seguro-desemprego podia durar 32 meses, em um valor de $60 \%$ a $70 \%$ do salário prévio.

11. Na Alemanha, reformas aprovadas em 2002 reduziram a proteção ao emprego para empresas com até dez trabalhadores. O seguro-desemprego foi reduzido para 12 meses (18 para maiores de 50 anos). Após esse período, o trabalhador poderia aplicar para um benefício básico de 345 euros.

12. Medidas foram também adotadas para elevar a idade de aposentadoria, reduzir o valor das pensões e reformar o sistema de saúde. A generosidade no valor dos benefícios foi preservada (Piersen, 2007).

13. Em 1950, cada aposentado era sustentado por oito pessoas ativas, número que caiu para quatro nos anos 1980 (Esping-Andersen, 2007:51).

14. Segundo Hay e Wincott (2012:127), incluindo os encarcerados, a taxa de sem emprego nos EUA tenderia a aproximar-se da média europeia.

15. Nos EUA, há a oferta de creches de baixa qualidade para as mães solteiras. As famílias que podem pagar recorrem às creches de qualidade do setor privado (Kerstenetzky, 2012:107). 


\section{Alexandre Queiroz Guimarães}

16. Apesar do crescimento no número de mães solteiras e de separações, houve pouco avanço nas políticas visando conciliar família e trabalho. França e Bélgica são exceções.

17. Em meados dos anos 2000, 70\% dos trabalhadores eram cobertos pelas negociações (Mailand, 2011).

18. O aparente paradoxo é explicado pelo fato de que as firmas não competem por baixo custo, considerando a mão de obra capacitada fundamental para o sucesso (Andersen e Svarer, 2007).

19. Segundo Steinmo (2013), a mesma só foi possível devido ao insulamento da classe política em relação a constituintes poderosos.

20. No regime escandinavo, segundo Kerstenetzky (2012:133), o índice de Gini era de 0,23 , contra 0,27 no regime continental e 0,32 no liberal.

21. A participação feminina no mercado de trabalho na Dinamarca e na Suécia era respectivamente de $75 \%$ e $78 \%, 25$ pontos percentuais acima da média da União Europeia.

22. Disponível em: <http://stats.oecd.org/>. 


\section{REFERÊNCIAS BIBLIOGRÁFICAS}

ANDERSEN, Torben M.; SVARER, Michael. (2007), “Flexicurity: Labour Market Performance in Denmark". CESifo Economic Studies, vol. 53, no 3, pp. 389-429.

ARRIGHI, Giovanni. (2008), Adam Smith em Pequim: Origens e Fundamentos do Século XXI. São Paulo, Boitempo.

AZEREDO, Beatriz. (1998), Políticas Públicas de Emprego. São Paulo, Unicamp/Instituto de Economia.

BECKER, Uwe. (2011), "Introduction", in U. Becker (org.), The Changing Political Economy of Small European States. Amsterdam, Amsterdam University Press, pp. 1-44.

; KERSBERGEN, Kees van. (2011), “The Small Corporatist Political Economies as European Socio-Economic Model?", in U. Becker (org.), The Changing Political Economy of Small European States. Amsterdam, Amsterdam University Press, pp. 173-197.

BORGES, Lucas; GUIMARÃES, Alexandre. (2011), As Políticas Públicas de Mercado de Trabalho: Novas Tendências e Desafios nos Países Desenvolvidos. Trabalho apresentado na 5th Brazilian Conference of Labor and Employment. São Paulo, Instituto Brasileiro de Relações de Emprego e Trabalho, 22-25 de agosto.

DAGUERRE, Anne. (2007), Active Labour Market Policies and Welfare Reform: Europe and the US in Comparative Perspective. Hampshire, Palgrave Macmillan.

EINHORN, Eric; LOGUE, John. (2010), “Can Welfare States Be Sustained in a Global Economy? Lessons from Scandinavia”. Political Science Quarterly, vol. 125, no1, pp. 1-29.

ESPING-ANDERSEN, Gosta. (1990), The Three Worlds of Welfare Capitalism. New Jersey, Princeton University Press.

. (2007), "The Sustainability of Welfare State into the 21th Century", in R. Vij (org.), Globalization and Welfare: A Critical Reader. New York, Macmillan, pp. 50-59.

GAMBLE, Andrew. (1988), The Free Economy and the Strong State. Durham, Duke University Press.

GOUREVITCH, Peter. (1986), Politics in Hard Times: Comparative Responses to International Economic Crises. Ithaca/London, Cornell University Press.

HAY, Colin e WINCOTT, Daniel. (2012), The Political Economy of European Welfare Capitalism. New York, Palgrave Macmillan.

HERMANN, Christoph. (2014), “Structural Adjustment and Neoliberal Convergence in Labour Markets and Welfare: The Impact of the Crisis and Austerity Measures on European Economic and Social Models". Competition \& Change, vol. 18, no 2, pp. 111-130.

JUDT, Tony. (2008), Pós-Guerra: Uma História da Europa desde 1945. Rio de Janeiro, Objetiva.

KATZENSTEIN, Peter. (1985), Small States in World Markets: Industrial Policy in Europe. Ithaca/London, Cornell University Press.

KERSTENETZKY, Celia L. (2012), O Estado do Bem-Estar Social na Idade da Razão: A Reinvenção do Estado Social no Mundo Contemporâneo. Rio de Janeiro, Campus/Elsevier. 


\section{Alexandre Queiroz Guimarães}

LINDGREN, Karl-Oskar. (2011), "The Variety of Capitalism in Sweden and Finland: Continuity through Change", in U. Becker (org.), The Changing Political Economy of Small European States. Amsterdam, Amsterdam University Press, pp. 45-72.

MAILAND, Mikkel. (2011), "Change and Continuity in Danish and Norwegain Capitalism: Corporatism and Beyond", in U. Becker (org.), The Changing Political Economy of Small European States. Amsterdam, Amsterdam University Press, pp. 73-97.

MARTIN, Cathie. (2004), "Reinventing Welfare Regimes: Employers and the Implementation of Active Social Policy". World Politics, vol. 57, pp. 39-69.

OLSON, Mancur. (1982), The Rise and Decline of Nations. New Haven, Yale University Press.

PIERSON, Paul. (2001), "Post-Industrial Pressures on the Mature Welfare States", in P. Pierson (org.), The New Politics of the Welfare State. Oxford, Oxford University Press, pp. 80-104.

. (2007), "The New Politics of the Welfare State", in R. Vij (org.), Globalization and Welfare: A Critical Reader. New York, Macmillan, pp. 147-159.

SCHWARTZ, Herman. (2001), "Round up the Usual Suspects! Globalization, Domestic Politics, and Welfare State Change", in P. Pierson (org.), The New Politics of the Welfare State. Oxford, Oxford University Press, pp. 17-44.

SEELEIB-KAISER, Martin; FLECKENSTEIN, Timo. (2007), “Discourse, Learning and Welfare State Change: The Case of German Labour Market Reforms". Social Policy \& Administration, vol. 41, no 5, pp. 427-448.

SMITH, Vivian. (2011), "Small Countries, Big Countries under Conditions of Europeanisation and Globalisation", in U. Becker (org.), The Changing Political Economy of Small European States. Amsterdam, Amsterdam University Press, pp. 149-171.

STEINMO, Sven. (2013), “Governing as an Engining Problem: The Political Economy of Swedish Success", in A. Schaffer e W. Streeck (orgs.), Politics in the Age of Austerity. Cambridge, Polity Press, pp. 84-107.

WEISHAUPT, J. Timo. (2011), From the Manpower Revolution to the Activation Paradigm: Explaining Continuity and Change in an Integrating Europe. Amsterdam, Amsterdam University Press. 


\section{RESUMO \\ Economia, Instituições e Estado de Bem-Estar Social: Respostas à Nova Configuração do Capitalismo pós-1970}

As décadas de 1950 e 1960 foram marcadas por grande prosperidade econômica e expansão dos Estados de Bem-Estar Social. Entretanto, dificuldades e mudanças marcaram os anos 1970. O artigo explora as respostas adotadas pelos países desenvolvidos às novas configurações do capitalismo, mostrando como foram influenciadas pelas instituições nacionais e pelo regime de Estados de Bem-Estar Social. Argumenta-se que os novos constrangimentos não conduziram à convergência nas estratégias e tampouco inviabilizaram este tipo de Estados. Dá-se especial atenção ao modelo escandinavo e à sua capacidade de conciliar bom desempenho e igualdade, enfatizando o papel das práticas corporativistas e da grande capacidade institucional. Em suma, o artigo discute pontos centrais no estudo da economia política ao lidar com um aspecto essencial para a legitimidade do capitalismo e ao explorar o impacto das instituições e mostrar que o capitalismo continua diverso.

Palavras-chave: Estado de Bem-Estar Social; instituições; neoliberalismo; modelo escandinavo; economia política

\section{ABSTRACT \\ Economy, Institutions and Welfare State: Responses to the New Configuration of Capitalism after 1970}

The 1950s and 1960s were a time of great economic prosperity and expansion of Welfare State. However, hardships and changes marked the following decade. This article explores how developed countries countered the new configuration of capitalism, showing how they were influenced by national institutions and by the welfare states regime. As a central point, the article shows that the new constraints did not lead to a convergence of strategies nor did they stymie the emergence of this type of State. The article focuses especially on the Scandinavian model and its ability to reconcile economic performance and equality, showing the role of corporativist practices and enhanced institutional capacity. In sum, the article discusses central points in the study of political economy in dealing with an essential aspect of the legitimacy of capitalism and in exploring the impact of institutions and showing that capitalism remains diverse.

Keywords: Welfare State; institutions; neoliberalism; Scandinavian model; political economy 
RÉSUMÉ

Économie, Institutions et État-providence: Réponses à la Nouvelle Configuration du Capitalisme post-1970

Les années 1950 et 1960 ont été marquées par une prospérité économique significative et l'expansion des États-providence. Des difficultés et autres changements marqueront néanmoins les années 1970. Cet article explore les réponses apportées par les pays développés aux nouvelles configurations du capitalisme pour dévoiler de quelle manière elles ont subi l'influence des institutions nationales et du régime de l'État-providence. Il s'agit essentiellement de montrer que les nouvelles contraintes n'ont pas mené à une convergence des stratégies ni à la remise en question définitive de ce type d'États. Une attention particulière sera portée sur le modèle scandinave et sa capacité à concilier les performances économiques et l'égalité, ainsi que sur le rôle qu'y jouent les pratiques corporatistes et les importantes capacités institutionnelles. En somme, cet article se penche sur des points centraux de l'étude de l'économie politique en prenant en compte un aspect essentiel à la légitimité du capitalisme, ainsi que l'impact des institutions, pour montrer finalement que le capitalisme demeure pluriel.

Mots-clés: État-providence; institutions; néolibéralisme; modèle scandinave; économie politique

\section{RESUMEN}

Economía, Instituciones y Estado de Bienestar Social: Respuestas a la Nueva Configuración del Capitalismo post-1970

Las décadas de 1950 y 1960 fueron marcadas por gran prosperidad económica y expansión de los Estados de bienestar social. Sin embargo, los años 1970 estuvieron marcados por dificultades y cambios. Este artículo explora las respuestas adoptadas por los países desarrollados a las nuevas configuraciones del capitalismo, mostrando las influencias de las instituciones nacionales y del régimen de Estados de bienestar social. Se argumenta que las nuevas sujeciones no condujeron a la convergencia de las estrategias ni tampoco inviabilizaron este tipo de Estados. Se presta especial atención al modelo escandinavo y a su capacidad de combinar buen desempeño e igualdad, con énfasis para el papel de las prácticas corporativistas y de la capacidad institucional. En definitiva, el artículo examina puntos centrales en el estudio de la economía política, explorando el impacto de las instituciones y examinando aspectos esenciales para la legitimidad del capitalismo, que sigue muy diverso.

Palabras clave: Estado de bienestar social; instituciones; neoliberalismo; modelo escandinavo; economía política 